\title{
Article \\ Coumarin 153 Dynamics in Ethylammonium Nitrate: The Effects of Dilution with Methanol
}

\author{
Mark P. Heitz *(1), Tyler J. Sabo and Stephanie M. Robillard
}

Citation: Heitz, M.P.; Sabo, T.J.; Robillard, S.M. Coumarin 153 Dynamics in Ethylammonium Nitrate: The Effects of Dilution with Methanol. Sustain. Chem. 2021, 2, 778-795. https://doi.org/ $10.3390 /$ suschem 2040041

Academic Editors: Ana B. Pereiro and Matthew Jones

Received: 8 November 2021 Accepted: 16 December 2021 Published: 20 December 2021

Publisher's Note: MDPI stays neutral with regard to jurisdictional claims in published maps and institutional affiliations.

Copyright: (c) 2021 by the authors. Licensee MDPI, Basel, Switzerland. This article is an open access article distributed under the terms and conditions of the Creative Commons Attribution (CC BY) license (https:/ / creativecommons.org/licenses/by/ $4.0 /)$.
Department of Chemistry, School of Arts and Sciences, State University of New York, Brockport, NY 14420, USA; tylerjsabo@gmail.com (T.J.S.); srobi4@brockport.edu (S.M.R.)

* Correspondence: mheitz@brockport.edu

\begin{abstract}
Magic angle intensity decay and dynamic fluorescence anisotropy measurements were made on the binary solvent system composed of ethylammonium nitrate $\left(\left[\mathrm{N}_{2,0,0,0}{ }^{+}\right]\left[\mathrm{NO}_{3}{ }^{-}\right]\right.$, EAN) + methanol $(\mathrm{MeOH})$ across the complete EAN mole fraction range $\left(x_{I L}=0-1\right)$ using the neutral dipolar solute coumarin 153 (C153) at 295 K. Stokes-Einstein-Debye (SED) hydrodynamic theory was used as a model framework to assess the $\mathrm{C} 153$ rotational reorientation dynamics. Departure from stick SED prediction was observed (in contrast to literature reports that used cationic or anionic dyes) and indicated a significant influence of domain nanoheterogeneity on probe dynamics. Steady-state spectroscopy indicated minimal changes in spectral peak and width with mole fraction, except at $x_{I L}=0.3$ where absorption widths decreased by $\sim 170 \mathrm{~cm}^{-1}$, signaling that $\mathrm{C} 153$ sensed a change in solution heterogeneity. Magic angle intensity decays corroborated the steady-state observation and the excited-state lifetimes showed a marked change from $x_{I L}=0.2-0.4$ where EANEAN interactions became notably more significant. C153 average rotation times $\left(\left\langle\tau_{\text {rot }}\right\rangle\right)$ showed significant solvent decoupling with increased EAN. The rotational data were fit to a power law dependence, $\left\langle\tau_{\text {rot }}\right\rangle \propto\left(\frac{\eta}{T}\right)^{p}$, where $p=0.82$, demonstrating the presence of dynamic heterogeneity in the EAN/MeOH solutions. With increased EAN, rotation times showed that the heterogeneity became increasingly more significant since the rotation times systematically decreased away from the hydrodynamic stick limit.
\end{abstract}

Keywords: ethylammonium nitrate; ionic liquid; coumarin 153; C153; rotational dynamics; SED hydrodynamics

\section{Introduction}

The canonical ionic liquid, ethylammonium nitrate (EAN, Scheme 1), was reportedly identified by Paul Walden more than a century ago. Since then, room temperature ionic liquids have been intensively studied and become a very popular medium for synthetic chemistry and various applications [1-5]. Protic ionic liquids (PILs) are among the most studied and reviews have discussed structure-property relationships, physicochemical properties, electrochemical, chromatographic and synthetic applications $[3,6]$. There is a large body of experimental and computational work that has communicated physicochemical properties [3,6-13], and described cosolvent interactions with organic solvents [7-10,12,14,15].

Solvation in ILs is often probed using a dye molecule to measure spectral shift (absorption or emission) and Stokes shift changes upon solvent reorganization. The time dependence of the Stokes shift is determined from time-resolved emission spectra (TRES) and gives some insight on the overall probe solvation dynamics. Dynamic anisotropy measurements yield a different measure of solute-solvent interactions through examining the viscosity coupling (microscopic friction) to the solvent system. In IL systems, solvation dynamics have been described using computer simulations [15-20], Stokes shift measurements [21-28], and rotational dynamics [21,22,29] measurements. The basic starting point for comparisons from these measurements is to use the results to evaluate the solution 
behavior against simple hydrodynamic theory, e.g., Debye-Stokes-Einstein (DSE) behavior [30]. According to the DSE description, a solute should experience the viscous drag of the first solvent shell as it moves through solution. Departures from hydrodynamic behavior can be correlated to many phenomena such as specific solute-solvent interactions (e.g., hydrogen bonding, electrostatic interactions, solvophobic interactions) [31] and "jump" mechanisms [32,33] where a molecule moves in a rapid angular (rotational) manner, but does so with nondiffusive motion, usually on an ultrafast time scale.

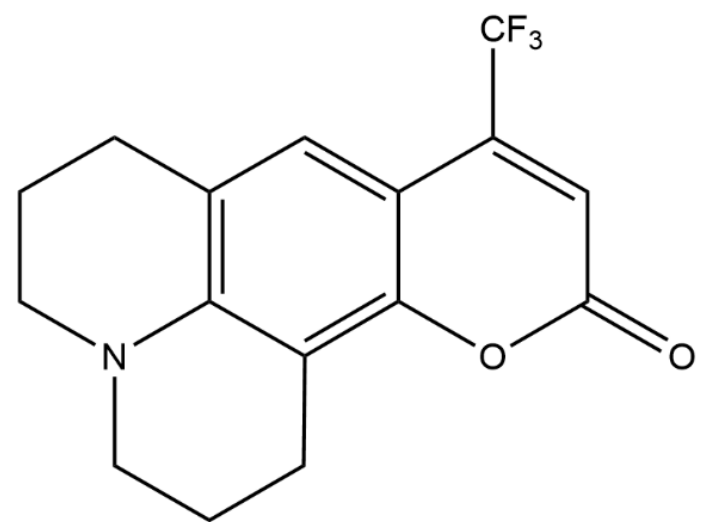

C153

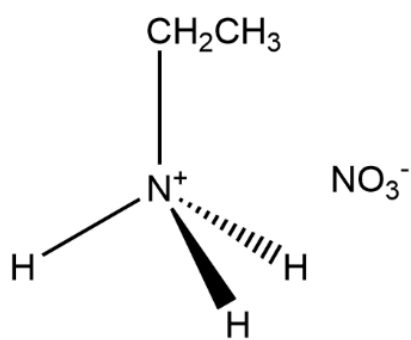

EAN

Scheme 1. Structures of coumarin 153 (C153) and ethylammonium nitrate (EAN).

In simple dipolar solvents, reorganization dynamics are linked to solute coupling primarily through dipole-dipole forces, whereas the dynamics in IL and IL + cosolvent are more complex resulting from solute, cosolvent, and ion pair interactions. In neat ILs, ion-dipole (i.e., IL-solute) forces are typically the most significant interactions $[26,34,35]$ but solvent-solvent interactions such as occurs through ion-ion interactions, dispersion forces, and dipolar forces also contribute to the overall IL solvation characteristics $[14,20,26,36,37]$. A molecular cosolvent adds more complexity by introducing additional forces that depends on the nature of the chosen cosolvent/IL pair, which has been discussed using a theoretical perspective $[27,28]$. In both neat ILs and IL/solvent mixtures one expects the solvation dynamics to be responsive to the varying types of molecular interactions; however, this is not always the case [24,25,35,38,39]. Samanta, using coumarin 153 (C153, Scheme 1) reported that nonpolar solvents added to 1-butyl-3-methylimidazolium hexafluorophosphate $\left(\mathrm{bmim}^{+} \mathrm{PF}_{6}{ }^{-}\right)$resulted in faster $\mathrm{C} 153$ rotational dynamics because of an increase in solution fluidity [38]. While the use of nonpolar solvents might be expected to have less impact on $\mathrm{C} 153$ rotational dynamics (from solvent coupling), one would expect that polar solvents would strongly influence the dynamics. However, Sarkar observed that for C153 rotational dynamics the addition of both protic and aprotic type polar solvents added to 1-hexyl-3-methylimidazolium hexafluorophosphate $\left(\mathrm{hmim}^{+} \mathrm{PF}_{6}{ }^{-}\right)$resulted in faster probe rotational reorganization [39]. Whether the solvent was nonpolar, protic, or aprotic, it appears that the primary effect was assigned to a viscosity effect as opposed to invoking specific solute/cosolvent/IL interactions. Nonetheless, it was noted that the C153 rotational dynamics in binary IL + polar solvent mixtures was less pronounced compared to the binary mixtures of IL + aprotic solvent [39]. In other work, Maroncelli's group showed that the C153 solvation times in several IL classes (imidazolium, ammonium, and phosphonium) follows a well-defined linear correlation with viscosity that was a linear extension of that observed in conventional dipolar solvents $[24,25]$. To date, the role that IL-IL and/or IL + cosolvent interactions play in modified IL solutions remains a topic interest $[2,7,15,16,18,40-44]$.

While there has been much work done on EAN using experimental and computational approaches, there are still relatively few reports that have examined the direct 
influence of a simple alcohol cosolvent on the resulting solution dynamics using simple hydrodynamic theory as a means of assessing the experimental observations. Dynamical measurements from extrinsic probes provides a useful perspective for determining the range of effects of the molecular interactions that govern probe-solvent interactions. In a very recent report, Garrett-Roe and coworkers identified two sub-ensembles in EAN from $\mathrm{SCN}^{-}$vibrational and rotational relaxation using 2-D IR spectroscopy, giving yet further evidence of the dynamical heterogeneity that is observed in ILs [43]. Given the inherent nanoheterogeneity within ILs and IL solutions, we set upon the task of evaluating whether hydrodynamic theory provided a good description against which we could assess probe rotational motion in the $\mathrm{EAN} / \mathrm{MeOH}$ system. We also have examined the influence of solution organizational changes on probe rotational reorientation dynamics through the variation of EAN mole fraction using methanol as a diluent. For all optical spectroscopy reported in this work (both steady-state and time resolved fluorescence), the neutral solvatochromic probe $\mathrm{C} 153$ was used to measure the effects of compositional change in the EAN + methanol $(\mathrm{MeOH})$ binary mixture as the solution was concentrated in EAN. C153 was chosen for its well-characterized emission and its well-known sensitivity to its chemical environment $[30,45,46]$. We note here that Sarkar and co-workers have performed similar measurements in $\mathrm{EAN} / \mathrm{MeOH}$, where they examined the solution dynamics using the cationic dye rhodamine $6 \mathrm{G}$ and the anionic dye fluorescein [47]. These probes would be expected to probe specific regions within the solution structure because they are charged dyes, and therefore may additionally be influenced by specific interactions. For our measurements, we chose to use the C153 dye for the additional reason that it is a neutral dye, and although it will experience hydrogen bonding interactions, the added complication of charged interactions is not present. Herein, we begin with a presentation of the bulk property characterization in the form of viscosity measurements. We then turn to describe our spectroscopic observations, where we report the solution effects on the steady-state spectroscopy and subsequently the time-resolved fluorescence results including magic angle intensity decays and decays of fluorescence anisotropy (rotational relaxation). The latter forms the main framework for the solvation dynamics discussion in the EAN/MeOH solvent system.

\section{Materials and Methods}

Coumarin 153 (laser grade) was purchased from Exciton, Lockbourne, OH, USA, stored under desiccation, and used as received. EAN was from IoLiTec, Heilbronn, Germany and dried in a vacuum oven for $48 \mathrm{~h}$ at $40{ }^{\circ} \mathrm{C}$ prior to use. $\mathrm{MeOH}$ was HPLC grade from Fisher Scientific. To prepare a mole fraction solution, an aliquot of a stock $1 \mathrm{mM}$ $\mathrm{C} 153 / \mathrm{MeOH}$ was added to the $1 \mathrm{~cm}$ path length $23-\mathrm{Q}-10$ Spectrosil ${ }^{\circledR}$ quartz cuvette (Starna Cells, Inc., Atascadero, CA, USA), the desired amount of EAN was added and massed on a $0.1 \mathrm{mg}$ balance (Mettler Toledo, Columbus, OH, USA, model XS104) and then diluted with $\mathrm{MeOH}$. The $\mathrm{C} 153$ concentration was $10 \mu \mathrm{M}$ (optical density was always less than 0.1 ). The cuvette was always kept tightly stoppered to minimize any $\mathrm{MeOH}$ evaporative losses. The cuvette was repeatedly inverted until the solution was single-phased and equilibrated. All spectroscopic measurements were made on this solution prior to micro-pipetting additions of either $\mathrm{MeOH}$ or EAN to make the next mole fraction solution until the cuvette was full. In this way, we were able to minimize solution preparation errors and economize on component consumption. Solutions were always single-phased and optically transparent at all mole fractions studied. The uncertainty in mole fraction was less than $\pm 0.5 \%$.

The water content of each solution component was determined by Karl-Fischer coulometric titration using a Mettler Toledo C20 titrator equipped with a DM 143-SC double platinum pin electrode at $295 \mathrm{~K}$. Measurements were performed in at least triplicate and average values were $\mathrm{MeOH}$ water content was $130 \pm 2$ ppm and EAN was not more than $500 \pm 5 \%$ ppm water. Neat and cosolvent modified EAN viscosities were measured using an Anton-Paar AMVn automated rolling ball viscometer. Rolling angles were accurate to $0.1^{\circ}$ and temperature was controlled to $\pm 0.02 \mathrm{~K}$. Quartz capillary tubes were calibrated 
with Koehler ISO 17025 Viscosity Reference Standard, type S60 or type S600. A typical viscosity measurement varied temperature from 288 to $323 \mathrm{~K}$ and used six replicated (12 total rolls) at each temperature. Data were collected cyclically starting at low temperature, increasing to the maximum, and then cooling to the starting temperature. This allowed us to evaluate reproducibility and spot hysteresis effects. For all measurements, viscosity uncertainty was typically $\pm 1-2 \%$ and reproducibility was $\pm 0.5-1 \%$.

Steady-state absorption and fluorescence were measured with a Perkin-Elmer Lambda 800 UV-Vis spectrometer with $2 \mathrm{~nm}$ resolution and a Horiba Scientific (Piscataway, NJ, USA) Fluorolog-3 fluorescence spectrometer with $2 \mathrm{~nm}$ resolution, respectively. The fluorimeter is equipped with a single grating excitation monochromator and a double grating emission monochromator for enhanced stray light rejection. All spectra were blank subtracted and corrected for instrument responses. We have described our time-correlated single photon counting (TCSPC) instrument previously [21,42]. Briefly, photons from a $405 \mathrm{~nm}$ NanoLED (405-L) high output diode laser were passed through a polarizer prior to entering the sample. Emission photons were passed through an automated Glan-Thompson polarizer set at "magic" angle $\left(54.7^{\circ}\right)$ for lifetime measurements and spectrally resolved with the double grating monochromator and detected with an air-cooled IBH TBX 850 detector. For anisotropy measurements, the emission polarization was acquired parallel and perpendicular to the excitation polarizer. The instrument response function was measured using a scattering solution and was on the order of $170 \mathrm{ps}$. Time calibration of the counting electronics was 7.16 ps per channel. All decay data were measured at the peak of the steady-state emission with emission slits between 4-6 $\mathrm{nm}$. Intensity decay data were fit to a sum of exponentials models using an iterative reconvolution algorithm within the IBH DAS6 decay analysis software and the estimated effective time resolution was $\sim 50 \mathrm{ps,}$ which was also confirmed from replicate measurements. Reduced chi-squared values $\left(\chi_{\mathrm{r}}^{2}\right)$ for a fit was judged to be acceptable if $\chi_{\mathrm{r}}^{2}<1.2$.

\section{Results}

\subsection{Bulk Properties-Viscosity}

Viscosity was measured over a temperature range of 288-323 K and for all mole solution fractions, $x_{I L}=0$ to 1 . Figure 1 summarizes the results in two ways; the upper panel shows the viscosity dependence on EAN mole fraction and the lower panel presents the temperature dependence for all mole fractions. Both sets of data are typical of what is observed in IL/cosolvent solutions. The lines in each panel are regressions to the respective data sets. The mole fraction dependence in the upper panel appears linear only for $x_{I L} \geq 0.6$, where the viscosity decreased by a factor of $\sim 4.5$. The linearity in this mole fraction range was well represented by a linear regression of the form $\log (\eta)=\left(2.88_{3} \pm 0.08_{5}\right)$ $\log \left(x_{I L}\right)+\left(1.68_{6} \pm 0.01_{1}\right)$. While it is certain that ion association plays a significant role in EAN-rich solution interactions, it seems that viscosity itself is not sensitive to any variations in this region. However, for $x_{I L}<0.6$, the viscosity changes by roughly an order of magnitude and $\Delta \log (\eta)$ shows a significantly non-linear dependence on $x_{I L}$. It is important to take note of this non-linearity because this response is indicative of more substantial changes occurring in dilute EAN solution [20,48,49]. The EAN/MeOH mixture in the low EAN concentration region is more strongly dominated by hydrogen bonding between $\mathrm{MeOH}$ and the EAN ions and the details from x-ray and neutron scattering provide ample evidence for this observation [49]. From the data here, viscosity appears to vary uniformly above $x_{I L}=0.6$. In other words, dilution with $\mathrm{MeOH}$ seems to result in a predictable, systematic variation of solution organization, but with an increase in fluidity that is particularly effective below $50 \mathrm{~mol} \%$ EAN. For completeness, we include the excess viscosities in Supplementary Materials Figure S1. These data were computed from:

$$
\eta^{E}=\eta_{\text {mix }}-\left[x_{E A N} \eta_{E A N}+\left(1-x_{E A N}\right) \eta_{M e O H}\right]
$$

where $\eta_{\text {mix }}$ is the measured EAN/MeOH mixture viscosity, $\eta_{E A N}$ and $\eta_{M e O H}$ are the pure component viscosities, and $x_{E A N}$ is the EAN mole fraction. $\eta_{E}$ values were fitted to a 
two component Redlich-Kister polynomial (see Supplementary Materials) [50]. Excess viscosities showed negative deviations for all mole fractions with the greatest deviation occurring at $x_{I L}=0.6$. Our results are in excellent agreement with results from Sarkar, who also observed a minimum in excess viscosity at exactly $x_{I L}=0.6$ in EAN/MeOH [47]. While we cannot infer any specific differentiation between the competing interactions from these data, we can be sure that there is a significant change in bulk composition $x_{I L}=0.6$ that likely signals that the $\mathrm{MeOH}$ impact has reached a climax as the mixture richens in EAN.
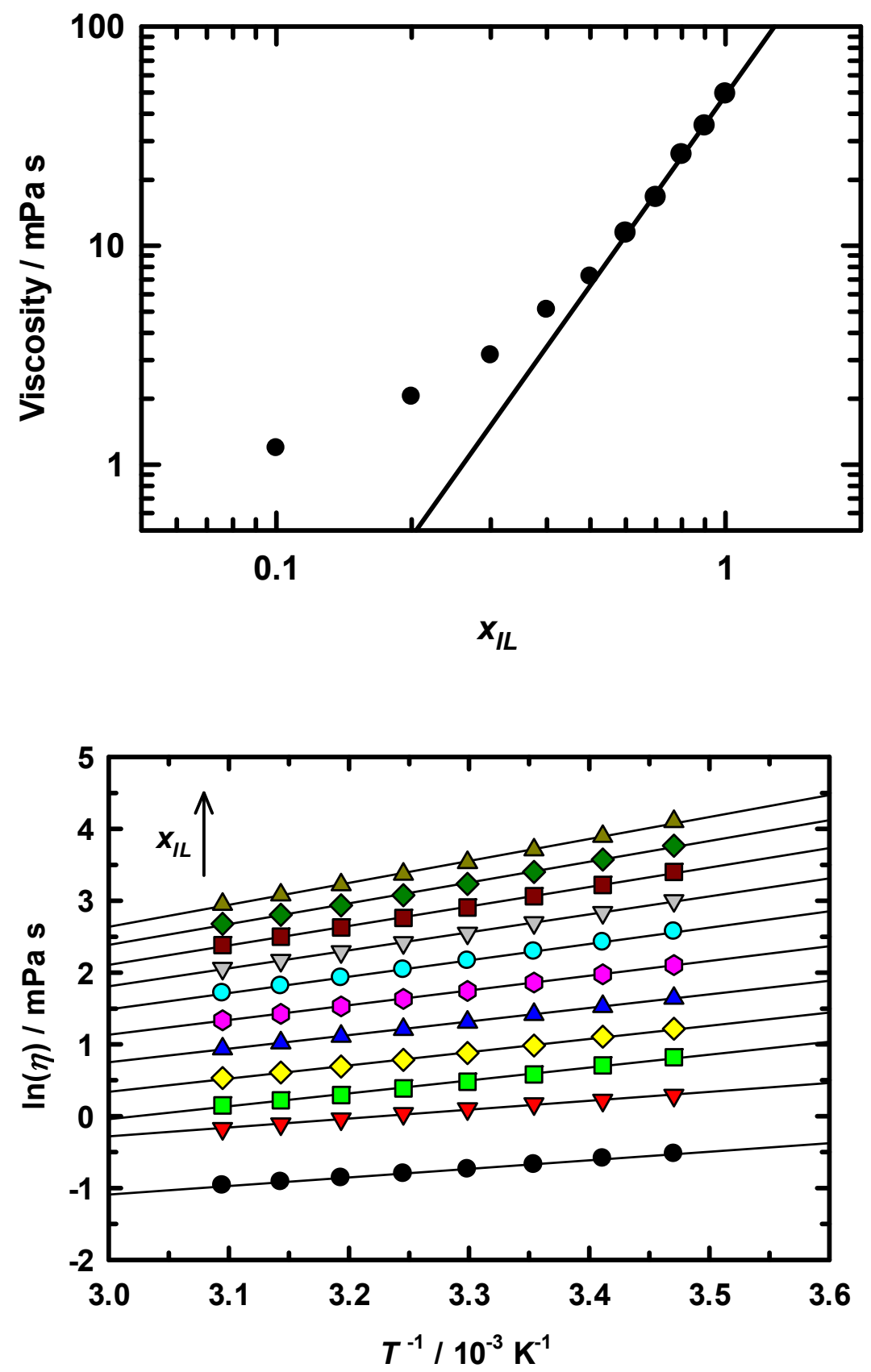

Figure 1. Upper panel: viscosity dependence on IL mole fraction for EAN/MeOH solutions at $295 \mathrm{~K}$. Line shown is a second order polynomial regression of the data and fits to the functional form: $\ln (\eta)=\left(-1.40 \pm 0.2_{5}\right) x_{I L}{ }^{2}+\left(5.7 \pm 0.2_{6}\right) x_{I L}-\left(0.47 \pm 0.05_{5}\right), r^{2}=0.998$. Lower panel: temperature dependent viscosities for each $x_{I L}$ solution. Mole fraction is increasing upward across the data set.

In contrast to the mole fraction results, the temperature dependence of viscosity is linear for all mole fractions and at all temperatures (see lower panel of Figure 1). Although we do not examine the temperature dependence of the spectroscopy and dynamics in this 
report, we are currently working on this as part of an extension to this work. Nonetheless, we have included the temperature dependent viscosity data in part to show that for any single mole fraction the viscosity suggests no obvious temperature effect, e.g., the temperature variation is linear at all mole fractions. It is interesting to note that for a given solution composition $\left(x_{I L}\right)$ there seems to be no specific influence from temperature except to increase solution fluidity. The $\eta^{E}$ data also show little variation in the overall pattern as a function of temperature, with the observed minimum remaining consistent at $x_{I L}=0.6$. However, in addition to the viscosity data, it is useful to examine the activation energies for viscous flow. To compute these values, the viscosity data were modeled using the Arrhenius activation model:

$$
\ln (\eta / m P a \cdot s)=\left(\frac{-E_{a}}{R}\right) \frac{1}{T / K}+\ln \left(\eta_{0} / m P a \cdot s\right)
$$

where $E_{a}$ is the activation energy for viscous flow, $R$ is the gas constant and $T$ is temperature in Kelvins. From these regression slopes, we have computed the activation energy for viscous flow at each solution mole fraction and summarized the results in Figure 2. The linearity of the EAN activation energy is in stark contrast to the non-linear behavior that we observed for the trihexyltetradecylphosphonium chloride $\left(\mathrm{P}_{14,6,6,6}{ }^{+} \mathrm{Cl}^{-}\right) / \mathrm{MeOH}$ system [50]. The structural contrast between these ILs is clearly different and demonstrates the significant contribution of long alkyl chains, which results in substantially enhanced entanglement as neat IL is approached in $\mathrm{P}_{14,6,6,6}{ }^{+} \mathrm{Cl}^{-}$compared to the EAN $\mathrm{C}_{2}$ chains. EAN has comparatively weaker interactions with $\mathrm{MeOH}$ than does the phosphonium example as $E_{a, E A N}$ is approximately $50 \%$ that of $\mathrm{P}_{14,6,6,6}{ }^{+} \mathrm{Cl}^{-} / \mathrm{MeOH}$ at comparable mole fraction solutions. The increase in activation energy with mole fraction supports the perspective of a general increase in dipolar interactions (e.g., ion-ion or ion-molecule association) the bulk solution effect scales well with composition. We note one further point of interest. Closer examination of the activation energies reveals that at $x_{I L}=0.2$ and 0.3 the values lie above the linear regression and the uncertainty in these values shows that this deviation is significant. Although the viscosity data do not reveal any extreme deviation, it is clear from the activation energy that the solution composition does reveal subtle differences for these mole fractions.

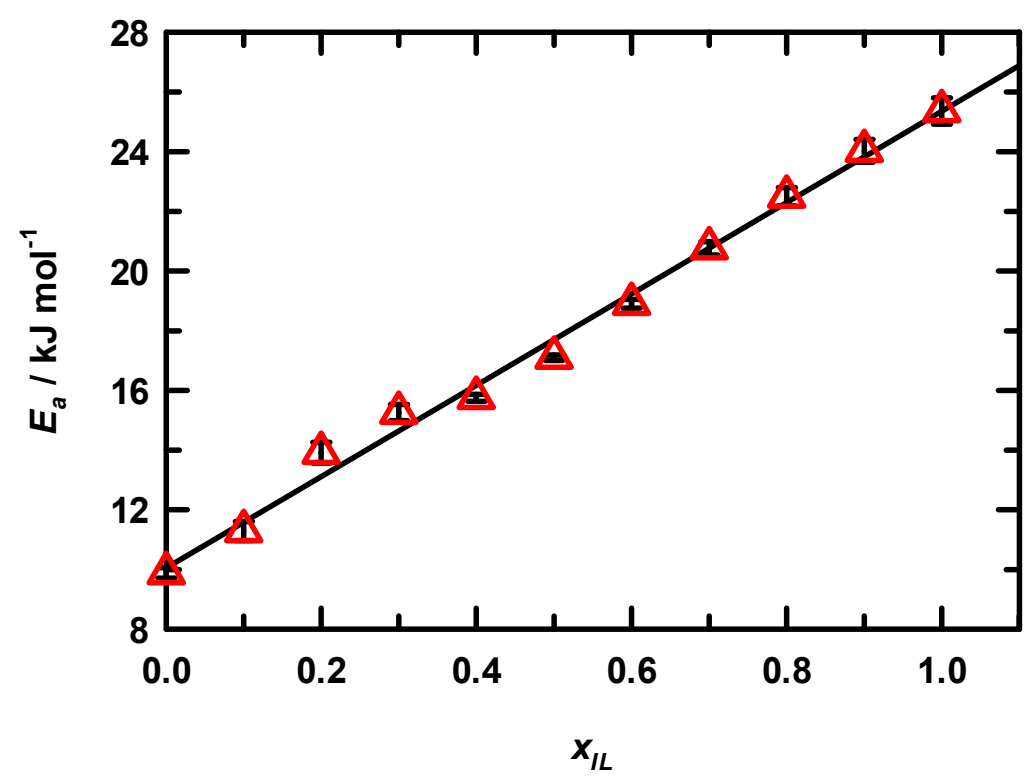

Figure 2. Arrhenius activation energy for viscous flow in EAN/MeOH solutions as a function of mole fraction. Symbols are sized to represent the experimental uncertainties. Line shown here is a first order polynomial regression, which yields the relation: $E_{a}=\left(15.30 \pm 0.4_{3}\right) x_{I L}+\left(10.0_{6} \pm 0.2_{6}\right)$, $r^{2}=0.993$. 


\subsection{Steady State Spectroscopy}

Steady-state absorption and emission spectra of neat EAN and C153/EAN/MeOH solutions were measured as a function of $x_{I L}$ in $\mathrm{MeOH}$. A set of representative steady-state emission spectra are presented in Figure 3 for $x_{I L}=0.1,0.4,0.6$, and 1.0 EAN in $\mathrm{MeOH}$. The spectra here are consistent with what is observed in simple dipolar solvents, and moreover are similar to what is observed in various ILs independent of cation/anion pairings [39,51-53]. As usual, spectra are featureless, and the spectra produce the typical log-normal line shapes. The set of spectra shown indicate that on first pass the microenvironment about the C153 probe appear to change very little in either peak position $\left(v_{\mathrm{pk}}\right)$ or in spectral width. Subsequent analysis results for $v_{\mathrm{pk}}$ and full width at half maximum (FWHM) for absorption and emission are presented in Figure 4 The upper panel gives results $v_{\mathrm{pk}}$ value for both absorbance (red symbols) and emission (green symbols) confirm this general observation. In the context of experimental uncertainty $\left(\sim 100 \mathrm{~cm}^{-1}\right)$, there is a significant, though subtle, bathochromic shift in both spectral measures of $\sim 450 \mathrm{~cm}^{-1}$ for absorbance and $290 \mathrm{~cm}^{-1}$. With regard to spectral widths, the absorption FWHM suggests a modest decrease in solution heterogeneity at $x_{I L} \sim 0.3$. The change in dipole moment upon C153 excitation is $\sim 8 \mathrm{D}$ based on in-house electronic structure calculations and in good agreement with literature reports [45]. Evidently, the increased polarity of the C153 excited state is sensitive to what, from our data, appears to be compositional changes as EAN is added to solution. Interestingly, excess volumes reported for EAN in cosolvents, including $\mathrm{MeOH}$ and acetonitrile, show a minimum at $x_{I L}=0.3$ and scattering studies therein confirmed the presence of mesoscopic solution organization $[7,14,20,36]$. EAN structural organization seems to be independent of the specific diluent. At the same time, $\mathrm{x}$-ray and neutron scattering showed that alcohol addition to EAN in small amounts does not alter the mesoscopic structure of neat EAN [20]. Finally, our activation energy results also confirm solution variation in the dilute EAN region. We also report the results of steady-state absorption and emission for C153 in neat EAN as a function of temperature ( $288 \mathrm{~K}-323 \mathrm{~K})$, which are presented as arrows at the right edge of Figure 4 . The values across the temperature range were constant to within experimental uncertainty. From our $\mathrm{C} 153$ spectroscopic perspective, either temperature variation seems to be an ineffective means of influencing the EAN solution structure or C153 does not adequately probe temperature effects.

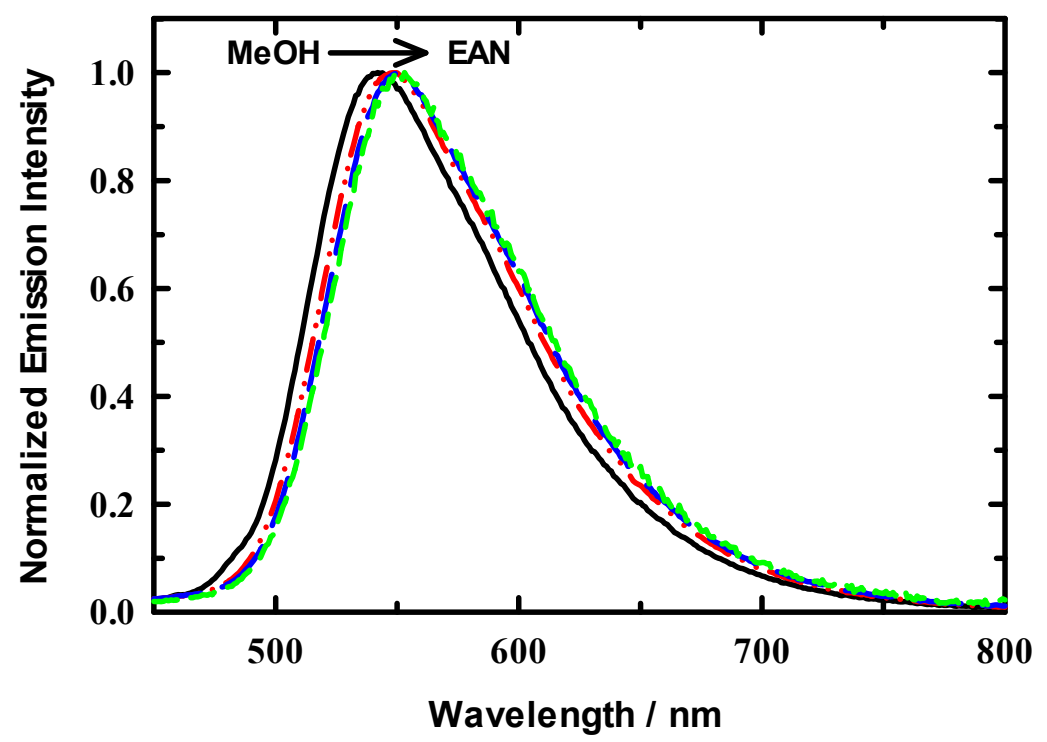

Figure 3. Representative normalized steady-state emission spectra for $\mathrm{C} 153$ in EAN/MeOH at $295 \mathrm{~K}$. $\mathrm{EAN} / \mathrm{MeOH}$ mole fractions shown (left to right) are $x_{I L}=0.1,0.4,0.6,1.0$. 


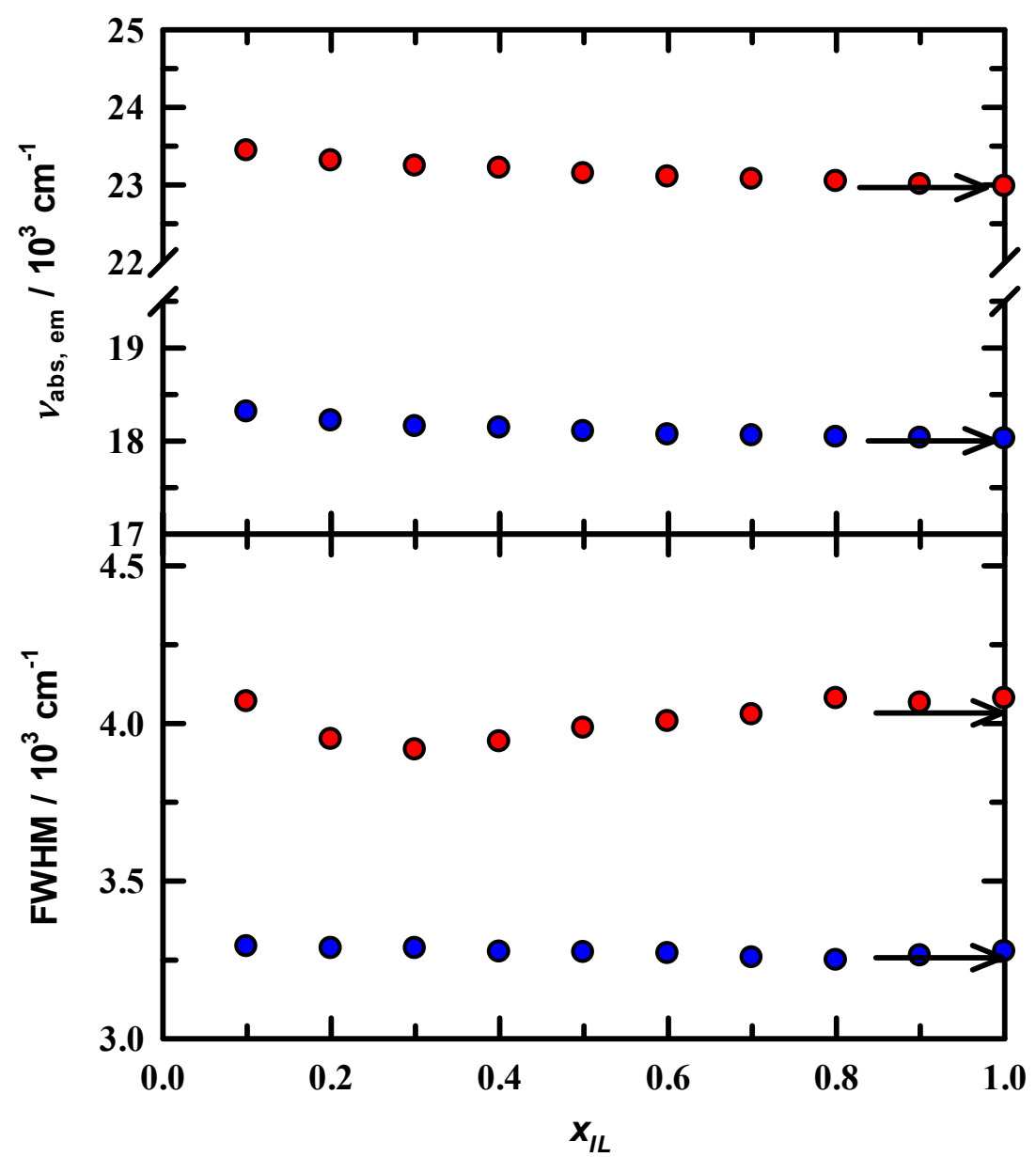

Figure 4. Steady-state spectral parameters for C153/EAN/MeOH. Red symbols are absorbance data and blue circles are emission data. Arrows indicate the spectral maxima and widths of C153/EAN temperature dependent data. The values indicated by the arrows were invariant over the temperature range measured (see text).

\subsection{Time-Resolved Spectroscopy}

We turn to the measured intensity decays for C153 in the binary mixtures at $295 \mathrm{~K}$. Here, the decays were measured at the peak of the spectral emission. Figure 5 shows two examples of the intensity decays (blue and green dotted symbols) in the bottom panel along with fits to those decays represented as solid lines. Weighted residuals of the fits are presented in the middle and upper panels. The data shown here are for $x_{I L}=0.1$ (curve $\mathrm{a}$, blue) and 0.8 (curve $\mathrm{b}$. green). We note a few points from these data. First, as the amount of EAN in solution is increased, the decays move to shorter time. Second, the residuals for the fits to simple sum of exponential models indicates that for dilute EAN solution (blue traces) it is difficult to appreciate the improvement in the quality of the fits with additional time constants. At higher $x_{I L}$, here $0.8 \mathrm{EAN}$, the C153 decay is clearly non-exponential, and requires more than a single time constant to adequately represent the intensity decay (note the residual comparison in panel (b) for time $<5 \mathrm{~ns}$ ). Residuals are typically the metric of assessing quality of fits, but importantly, in addition to using the residuals as a metric for quality of fits we also examined the autocorrelation of the residuals (see Supplementary Materials Figure S2), which is more sensitive to variations in the fitting parameters. From the autocorrelations, in concert with residuals, we were able to make more confident determinations as to whether we included an additional time constant. Criteria that are used to determine if the data require additional time constants are (1) a threshold of $10 \%$ improvement in $\chi_{\mathrm{r}}^{2}$; (2) a significant improvement in the randomness of the residuals; and (3) significant improvement in the autocorrelations of the residuals. 


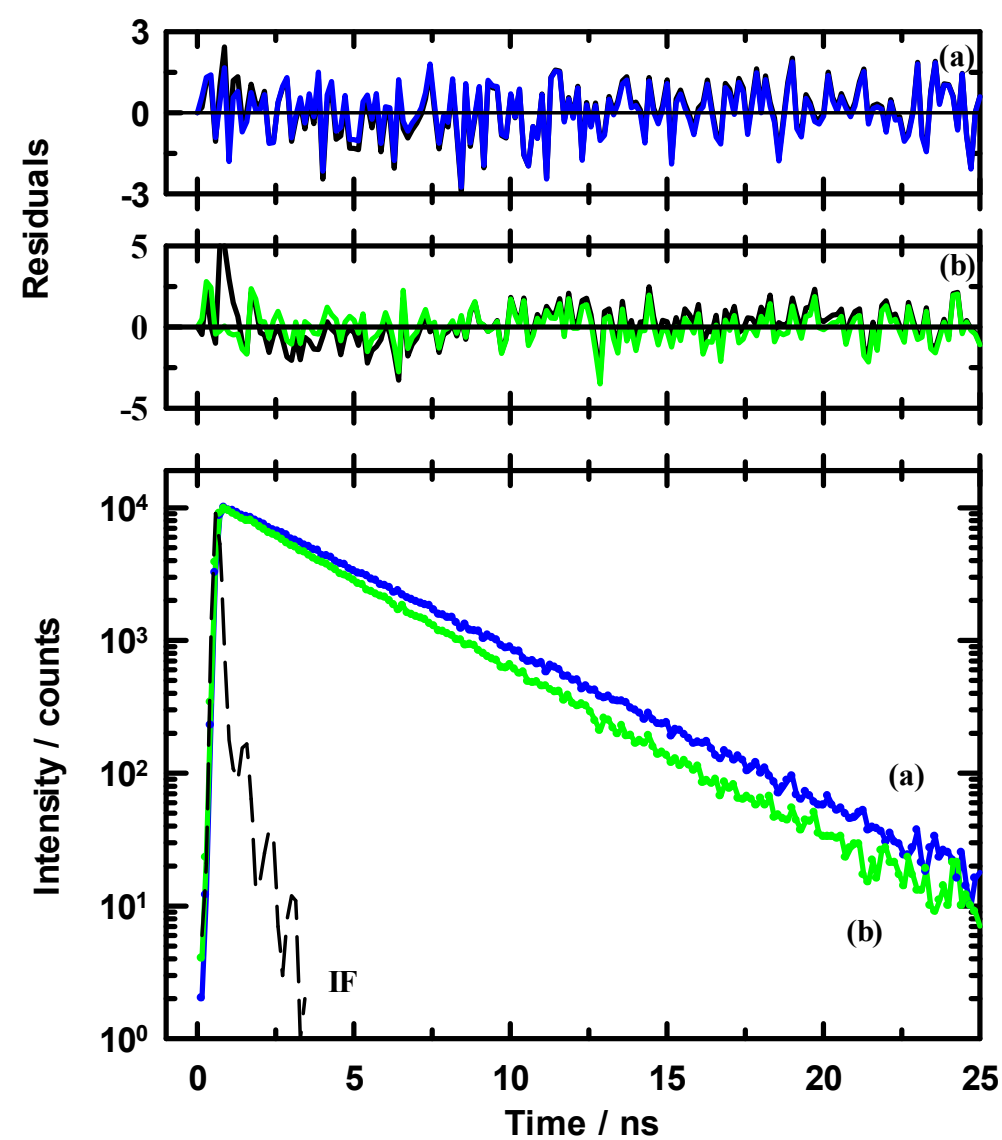

Figure 5. Examples of magic angle fluorescence intensity decays for C153 in EAN / MeOH at $295 \mathrm{~K}$. The bottom panel shows decay data for $(\mathbf{a}, \mathbf{b l u e}) x_{I L}=0.1$ and $(\mathbf{b}$, green $) x_{I L}=0.8$. Data are thinned by a factor of 10 for added clarity. The dashed line labeled "IF" is the instrument response function. The upper panels show the weighted residuals (thinned by $10 \times$ ) at each of the mole fractions: (a) $x_{I L}=0.1$, blue line, using two time constants in the decay model and (b) $x_{I L}=0.8$, green line, using three time constants in the decay model. The black line in panel (b) shows the residuals for two time constants.

To begin, we note that within our time resolution $\mathrm{C} 153 / \mathrm{MeOH}$ exhibits a monoexponential decay and $\mathrm{C} 153$ senses only a bulk $\mathrm{MeOH}$ environment. The results of the intensity decay fits for the EAN/MeOH solutions are compiled in Table 1 and are presented in Figure 6, with lifetimes in the lower panel and associated fractional contributions in the upper panel.

Table 1. Results of EAN/MeOH Intensity Decay Fits at $295 \mathrm{~K}$.

\begin{tabular}{|c|c|c|c|c|c|c|}
\hline$x_{I L}$ & $f_{1}$ & $f_{2}$ & $\tau_{1} / \mathrm{ns}$ & $\tau_{2} / \mathrm{ns}$ & $\chi_{\mathrm{r}^{2}}$ & $\langle\tau\rangle /$ ns $^{\text {a }}$ \\
\hline 0 & & & $3.91 \pm 0.05$ & & & 3.91 \\
\hline 0.1 & $0.031 \pm 0.005$ & $0.968 \pm 0.006$ & $2.09 \pm 0.36$ & $3.70 \pm 0.01$ & 1.1 & 3.66 \\
\hline 0.2 & $0.448 \pm 0.024$ & $0.551 \pm 0.013$ & $3.11 \pm 0.15$ & $3.92 \pm 0.02$ & 1.1 & 3.56 \\
\hline 0.3 & $0.704 \pm 0.089$ & $0.295 \pm 0.021$ & $3.24 \pm 0.33$ & $3.99 \pm 0.04$ & 1.2 & 3.47 \\
\hline 0.4 & $0.589 \pm 0.018$ & $0.410 \pm 0.008$ & $3.04 \pm 0.07$ & $3.89 \pm 0.03$ & 1.1 & 3.39 \\
\hline 0.5 & $0.118 \pm 0.016$ & $0.881 \pm 0.014$ & $2.28 \pm 0.30$ & $3.49 \pm 0.01$ & 1.1 & 3.35 \\
\hline 0.6 & $0.021 \pm 0.001$ & $0.978 \pm 0.002$ & $0.56 \pm 0.03$ & $3.35 \pm 0.01$ & 1.1 & 3.30 \\
\hline 0.7 & $0.018 \pm 0.001$ & $0.981 \pm 0.002$ & $0.53 \pm 0.04$ & $3.31 \pm 0.01$ & 1.1 & 3.26 \\
\hline 0.8 & $0.022 \pm 0.001$ & $0.977 \pm 0.002$ & $0.54 \pm 0.03$ & $3.28 \pm 0.01$ & 1.1 & 3.22 \\
\hline 0.9 & $0.019 \pm 0.001$ & $0.980 \pm 0.001$ & $0.44 \pm 0.01$ & $3.24 \pm 0.01$ & 1.2 & 3.19 \\
\hline 1 & $0.028 \pm 0.002$ & $0.971 \pm 0.002$ & $0.70 \pm 0.05$ & $3.25 \pm 0.01$ & 1.2 & 3.19 \\
\hline
\end{tabular}

${ }^{a}$ The average lifetime is calculated using Equation (4). 


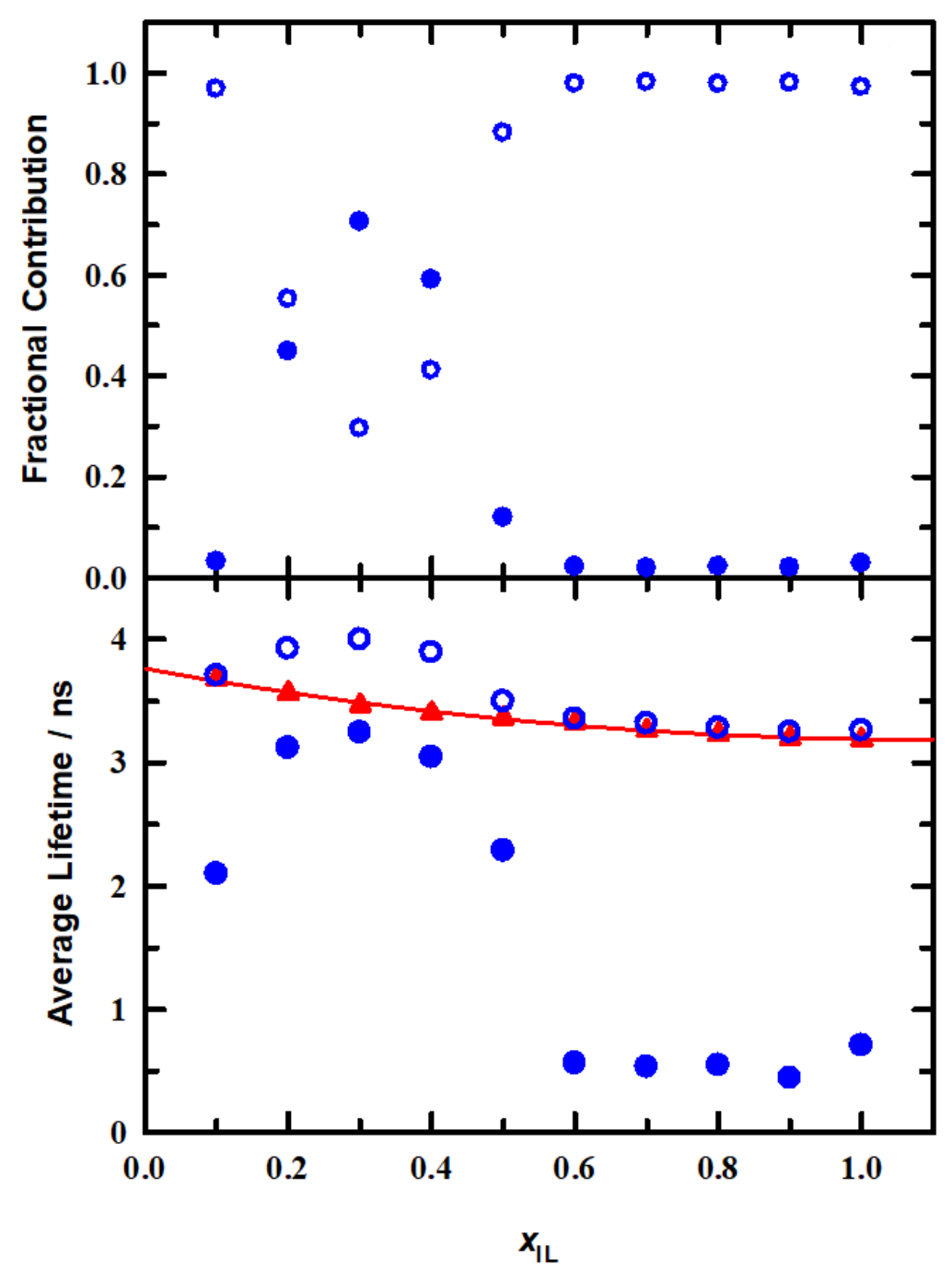

Figure 6. Time resolved intensity decay parameters for $\mathrm{C} 153$ in EAN/MeOH solutions at $295 \mathrm{~K}$. Fractional contributions and time constants from best fits to the intensity decays $(\bigcirc, \bullet)$. Average lifetimes $(\Delta)$ calculated using Equation (4). The line is a second order polynomial regression, $\tau_{\mathrm{fl}}=(0.49 \pm 0.07)$ $x_{I L}{ }^{2}-(1.06 \pm 0.08) x_{I L}+(3.76 \pm 0.02), r^{2}=0.992$, that is included primarily as a visual aid

Here, we include two representations of the data, the lifetime-weighted fractions and time constants (blue symbols) and the average lifetimes (red symbols) for each mole fraction. Fractions were calculated as:

$$
f_{i}=\frac{a_{i} \tau_{i}}{\sum_{i} a_{i} \tau_{i}},
$$

and weighted average lifetimes were computed using:

$$
\langle\tau\rangle=\frac{\sum_{i} a_{i} \tau_{i}^{2}}{\sum_{i} a_{i} \tau_{i}},
$$

where $a_{i}$ is the normalized un-weighted pre-exponential factors determined from the DAS-6 fitting parameters and $\tau_{i}$ is the component lifetime.

The $\mathrm{C} 153$ lifetime in neat $\mathrm{MeOH}$ is adequately described by a single time constant $3.9 \mathrm{~ns}$ and agrees with previous literature [21,54]. As is typical in dipolar solvents such as $\mathrm{MeOH}$ and ILs, the $\sim 4$ ns shows that substantial non-radiative relaxation is present, compared to gas phase intensity decay where the representative time constant is on the 
order of $\sim 6 \mathrm{~ns}$ [51]. We observe that for EAN/MeOH mixture data two time constants were required for all mole fractions. On initial addition of EAN $\left(x_{I L}=0.1\right)$ about $3 \%$ of the decay was contributed from the faster time constant. Between $x_{I L}=0.2-0.5$ there is a more substantial contribution from each of the two time constants, with a minimum that appears at $x_{I L}=0.3$. This minimum in the lifetime results is in good agreement with our steady-state results and aforementioned literature reports of EAN/MeOH solution organization $[7,14,20,36]$. Moreover, the lifetimes are suggestive that $\mathrm{C} 153$ interactions are differentiating between solution components and reflective of C153-EAN and C153-MeOH. Note that in the range $x_{I L}=0.2-0.5$ the faster time constant is $\sim 3 \mathrm{~ns}$, similar to the value of $\sim 3.2 \mathrm{~ns}$ for $x_{I L}=1$, and the slower time constant is consistent with the $\mathrm{C} 153 / \mathrm{MeOH}$ lifetime of $\sim 4 \mathrm{~ns}$. The relative contributions (fractions) give a commentary on the variation of these interactions. For solution compositions greater than $x_{I L}=0.6$ the decays were nearly exponential, requiring only $\sim 2 \%$ of a $\sim 0.5$ ns time constant. Intensity decay in neat ILs is typically non-exponential $[24,35,51,53,55]$, and the scope and complexity of interactions in neat ILs has been shown to require up to five exponentials to fully and adequately describe the intensity decay data [55]. Reports have suggested that ion translational/diffusional motions are collectively described by sub-picosecond dynamics and slower solvent dynamics [18,20,40,41,43,47]. Samanta described additional contributions to solute-solvent interactions, such as solvent shell reorganization, orientational relaxation, dipolar interactions, aggregate translation and rotation, etc., that will also influence the $\mathrm{C} 153$ emission [35]. For EAN/MeOH, as the solution is enriched in EAN $\left(x_{I L}>0.5\right)$ it is interesting to note that from the lifetime data alone one might infer that there appears to be little if any change in component interactions. This perspective is corroborated from diffraction measurements reported by Triolo and co-workers, where they show that at low alcohol concentration (here, larger $x_{I L}$ values) there is minimal influence by $\mathrm{MeOH}$ on the IL structure. Rather, it is on $\mathrm{MeOH}$ where there is significant impact to its microenvironment in that it is the methanol-methanol correlation that is significantly impacted [20]. The $\mathrm{C} 153$ radiative rates and fractions at smaller $x_{I L}$ values gives clear evidence that solute-solvent interactions are changing significantly as the complexity of the system is increased with added EAN. Finally, it is interesting to consider the average lifetime (triangles) data. These data are perhaps a bit deceiving in that they suggest a smooth variation in solute-solvent interactions across the compositional range. By that measure, one would miss the clear pattern shift at $x_{I L} \sim 0.3$. However, the average value does give the correct view for EAN at larger $x_{I L}$ values and indicates a nearly invariant lifetime as the influence of $\mathrm{MeOH}$ on EAN-MeOH interactions diminishes. Whatever specific micro- or nanoscopic organization (e.g., caging) drives the interactions that are attributable to the $0.5 \mathrm{~ns}$ contribution to the lifetime beyond $x_{I L}=0.5$, this time constant contributes at most $2.5 \%$ to the $\mathrm{C} 153$ decay kinetics. We now examine the $\mathrm{C} 153$ rotational dynamics for the $\mathrm{EAN} / \mathrm{MeOH}$ binary solutions.

\subsection{Rotational Dynamics}

Fluorescence decays of anisotropy were measured at the emission maxima for each mole fraction. Supplementary Materials Figure S3 shows representative polarized intensity decay data at $x_{I L}=0.2$ and 0.9 . The polarized intensity decays were fit using a reconvolution sum of exponentials model:

$$
r(t)=r_{0}\left[\sum_{i=1}^{n} f_{i} \exp \left(\frac{-t}{\tau_{r o t, i}}\right)\right],
$$

where $r_{0}$ is the initial anisotropy, $f_{i}$ is the normalized pre-exponential factor and $\tau_{r o t, i}$ is the rotation time. C153 limiting anisotropy values have been measured and discussed in detail elsewhere [30]. The accepted $r_{0}$ value is 0.373 but was shown to range from 0.33 to 0.39 . We used $r_{0}$ as a variable fitting parameter in our analysis to test whether our data are capturing the entire anisotropy decay. Results of the fits are noted in Table 2 . The values for $r_{0}$ indicate that for the two most dilute EAN solutions, we are missing $\sim 22 \%$ initial 
decay because our time resolution is unable to detect the faster ps and sub-ps motions that are surely in the dynamics. When fixing $r_{0}$ to 0.37 the rotation times are 75 and 135 ps for $x_{I L}=0.1$ and 0.2 , respectively, a decrease in the reported times of about $30 \%$ each. However, this does not change the observed trend. Further, we note that for $x_{I L}>0.2$ the recovered $r_{0}$ values are within uncertainty of the expected range, showing that we are capturing the rotational diffusion that occurs within the ml153 lifetime. For $x_{I L}$ values 0.6 and greater, the $\mathrm{C} 153$ rotational dynamics require two time constants to model the decay and this is consistent with an the increased solution complexity of interactions. Table 2 also reports the average rotation times $\left(\left\langle\tau_{r o t}\right\rangle\right)$ and uncertainties in these data are at most $6 \%$. Figure 7 depicts the rotation time dependence on solution viscosity and we observe that at first glance the increase in time constants parallels increasing viscosity.

Table 2. Results of EAN/MeOH Anisotropy Decay Fits at $295 \mathrm{~K}$.

\begin{tabular}{|c|c|c|c|c|c|c|c|c|}
\hline$x_{I L}$ & $\eta / \mathrm{mPa} \cdot \mathbf{s}$ & $r_{0}$ & $f_{1}{ }^{a}$ & $\tau_{1} / \mathrm{ns}$ & $\tau_{2} / \mathrm{ns}$ & $\chi_{\mathrm{r}}^{2}$ & $\langle\tau\rangle / \mathbf{n s}^{\mathbf{b}}$ & $C_{o b s}$ \\
\hline 0 & 0.54 & & $1.00^{b}$ & $0.04 \pm 0.01$ & & & & $0.61 \pm 0.09$ \\
\hline 0.1 & 1.2 & 0.28 & $1.00 \pm 0.04$ & $0.11 \pm 0.01$ & & 1.02 & 0.11 & $0.90 \pm 0.04$ \\
\hline 0.2 & 2.0 & 0.29 & $1.00 \pm 0.02$ & $0.18 \pm 0.01$ & & 1.11 & 0.19 & $0.89 \pm 0.04$ \\
\hline 0.3 & 3.2 & 0.36 & $1.00 \pm 0.01$ & $0.28 \pm 0.01$ & & 0.98 & 0.28 & $0.87 \pm 0.04$ \\
\hline 0.4 & 5.1 & 0.32 & $1.00 \pm 0.01$ & $0.43 \pm 0.01$ & & 1.08 & 0.44 & $0.83 \pm 0.03$ \\
\hline 0.5 & 7.2 & 0.32 & $1.00 \pm 0.01$ & $0.58 \pm 0.01$ & & 1.14 & 0.59 & $0.79 \pm 0.03$ \\
\hline 0.6 & 11.4 & 0.38 & $0.24 \pm 0.04$ & $0.47 \pm 0.07$ & $1.04 \pm 0.02$ & 1.07 & 0.91 & $0.77 \pm 0.04$ \\
\hline 0.7 & 16.6 & 0.35 & $0.11 \pm 0.01$ & $0.50 \pm 0.06$ & $1.34 \pm 0.01$ & 0.95 & 1.25 & $0.73 \pm 0.03$ \\
\hline 0.8 & 26.0 & 0.34 & $0.03 \pm 0.01$ & $0.42 \pm 0.08$ & $1.65 \pm 0.01$ & 1.00 & 1.51 & $0.56 \pm 0.02$ \\
\hline 0.9 & 35.2 & 0.36 & $0.02 \pm 0.01$ & $0.35 \pm 0.03$ & $2.10 \pm 0.01$ & 1.06 & 2.07 & $0.57 \pm 0.02$ \\
\hline 1 & 49.2 & 0.38 & $0.01 \pm 0.01$ & $0.24 \pm 0.03$ & $2.24 \pm 0.01$ & 1.09 & 2.22 & $0.44 \pm 0.02$ \\
\hline
\end{tabular}

a Fractional contributions sum to 1 , and $f_{2}=1-f_{1}$ and where two time constants are reported uncertainties in $f_{2}$ were identical to those of $f_{1} \cdot{ }^{\mathrm{b}}$ The average rotation time is calculated using $\sum_{i} f_{i} \tau_{i}$.

The red triangles below $x_{I L}=0.6$ are the monoexponential times whereas the blue spheres indicate the mole fractions requiring two rotation times. In addition to the smaller mole fractions, red triangles at $x_{I L}=0.6$ and above represent the average rotation times. Figure 7 also includes the computed hydrodynamic times for stick and slip boundary conditions, where the stick limit is reflective of the probe's rotation including the first solvent shell and in the extreme slip limit the lack of solvent drag [56,57]. Stick and slip hydrodynamic limits for rotational diffusion are computed using the relation:

$$
\tau_{\text {hyd }}=\frac{\eta V}{k_{B} T} f C,
$$

where $V$ is $C 153$ volume, $f$ is a shape factor, and $C$ is a coupling factor. Molecular parameters were determined by modeling C153 as an ellipsoid with semi-axis dimensions of 2.0, 4.8, and $6.1 \AA$, yielding a molecular volume $V=246 \AA^{3}$, and with $f=1.71$. The coupling factor $C=1$ and $C=0.24$ are for the stick and slip limits, respectively [30]. The average rotation times are lie near the stick limit up to $x_{I L}=\sim 0.6$, after which the values decrease more substantially from the hydrodynamic limit. The correlation to hydrodynamic behavior is quantified from $C_{o b s}$ as:

$$
C_{o b s}=\frac{k_{B} T}{\eta V f}=\frac{\left\langle\tau_{\text {rot }}\right\rangle}{\tau_{\text {stick }}},
$$

and are presented in the upper panel of Figure 7. The open square is $\mathrm{C} 153$ in neat $\mathrm{MeOH}$ measured at $22{ }^{\circ} \mathrm{C}$ using femtosecond up-conversion [30]. Immediately upon addition of EAN C153 rotations times show a distinct difference compared to $\mathrm{MeOH}$ and even with the initial addition follow the stick limit hydrodynamic prediction. $C_{o b s}$ shows that the dynamics are nearly hydrodynamic at $\sim 90 \%$ of the stick limit and drop precipitously as EAN is added. At the split in rotation times the faster time contributes $\sim 25 \%$ to the decay and steadily decreases to a $1 \%$ contribution in EAN. It appears that C153 experiences a 
solution heterogeneity, which becomes very prominent at about $50 \mathrm{~mol} \%$ and remains detectable even in neat EAN. The rotation data give evidence that the solution complexity is consistently increasing as the deviation from hydrodynamic becomes significant as evidenced by $C_{o b s} \rightarrow 0.4$.

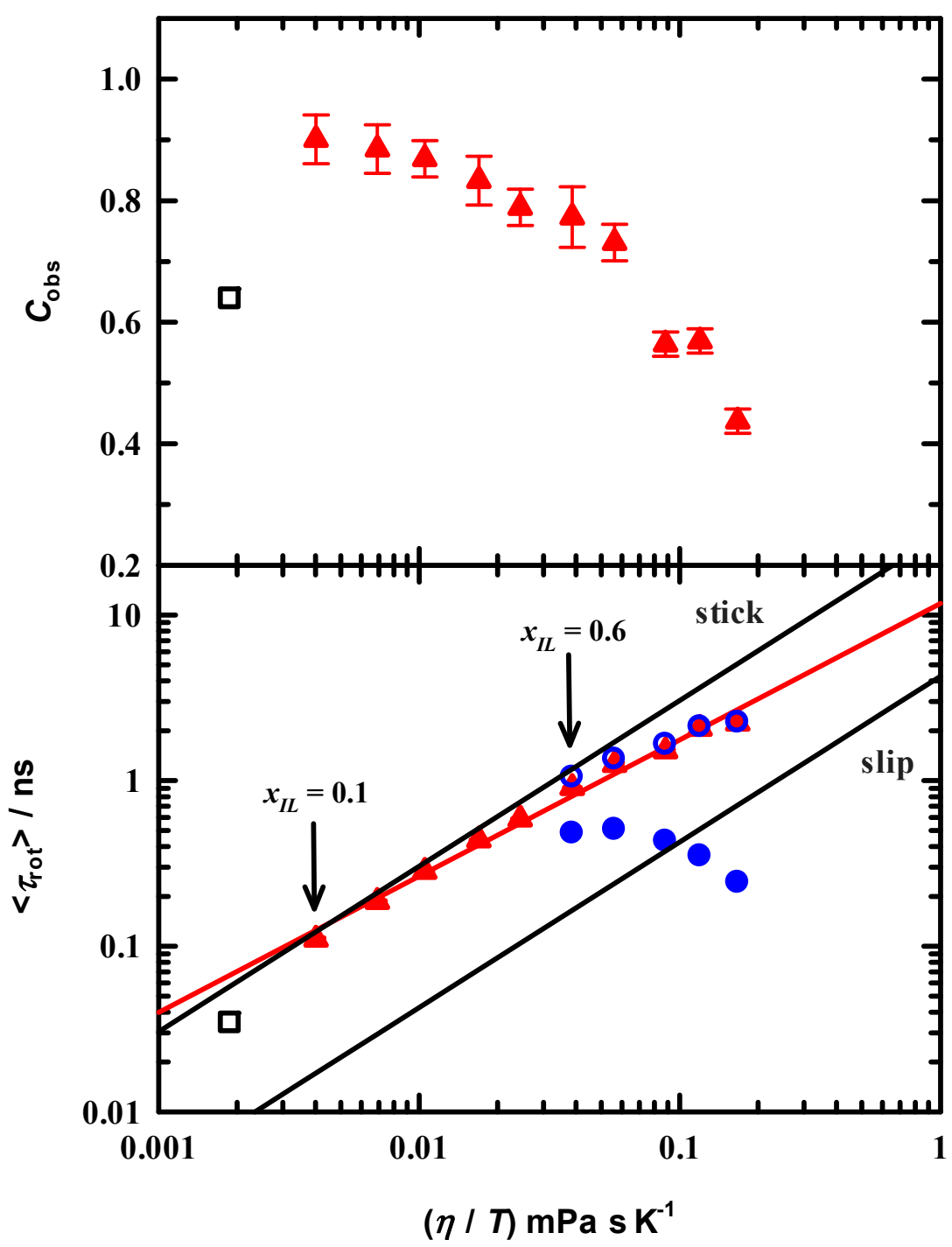

Figure 7. Lower Panel: Rotation times of C153 in EAN/MeOH at $295 \mathrm{~K}$. Symbols represent time constants for fits to the anisotropy decays. Data sets that required one time constant are shown with triangles $(\Delta)$, but only for $x_{I L}<0.6$, and data sets that required two time constants are the circles $(\bullet, \bigcirc)$. Triangles over the entire range are weighted average rotation time constants. The red line is a regression fit to these data only. The black lines show the predictions for stick and slip hydrodynamics. Upper Panel: Coupling factor, $C$, that indicates the fractional average rotation times relative to the stick prediction (see Equation (7)). The open square shows the values for $\mathrm{C} 153 / \mathrm{MeOH}$.

As a final point of analysis, we evaluated the rotational diffusion coupling to solution viscosity. Assuming the Stokes-Einstein-Debye hydrodynamic behavior in Equation (6), one expects that $\tau_{\text {hyd }} \propto\left(\frac{\eta}{T}\right)^{p}$ where $p=1$ in the stick limit and rotation correlates directly viscosity. Since the average rotation time seems to provide a reasonable estimate at all mole fractions, we regressed those times accordingly and found that the fit yielded a $p$ value of $0.82 \pm 0.03$, indicating the $\mathrm{EAN} / \mathrm{MeOH}$ solution is exhibiting dynamic heterogeneity. ILs nano- and microstructure tends to form polar and non-polar domains in varying degrees depending on solution constituents and the varieties of interactions that occur, which leads to both spatial (structural) and dynamic heterogeneities [10,11,18,43,47]. As a consequence 
of solution heterogeneity, we expect a distribution of microenvironments that manifest as viscosity variations in the bulk solution. Of particular interest for this work is the excess viscosity (Supplementary Materials Figure S2 and ref) that showed a substantial depression in the EAN/MeOH solution viscosity, with a decrease of about $-7 \mathrm{cP}$ at $298 \mathrm{~K}$ and as much as $-20 \mathrm{cP}$ at $278 \mathrm{~K}$. The change in our rotational dynamics from one-to-two time constants aligns well with the change in excess viscosity and it appears that from the perspective of heterogeneity the solution structure at $x_{I L}=0.6$ and above is significantly different. We attribute this observation to the existence of multiple IL domains that include both polar and apolar micro- and nanodomains.

\section{Discussion}

An extensive amount of experimental and simulation evidence exists in the literature supporting the structural heterogeneity of ILs and IL solutions, the source of which may arise from ion pair associations in neat IL and dilution effects in cosolvent modified ILs [58-62]. Extended aggregation also drives heterogeneity in ILs especially when the cation possesses longer alkyl chains $[21,63,64]$. For EAN with only a $C_{2}$ chain, aggregation is not a significant consideration, so what governs structural variation? Formation of hydrogen bonds between EAN, MeOH and C153 collectively would seem to account for the slowed hydrodynamic-like rotational dynamics as well as the formation of polar and apolar domains within the EAN structure, and these interactions have been discussed in detail elsewhere (and references above) $[18,31,36,65,66]$. Another point of importance is the various correlation lengths that exist in solution, including anion-anion, cation-anion, cation-cation interactions, that not only persist spatially but dynamically as well $[31,66]$. Correlation lengths in EAN were reported to be on the order of $\sim 10 \AA[31,66]$, and given that the semi-axes dimensions of the $\mathrm{C} 153$ ellipsoid are estimated to be $6.0 \AA$ and $4.8 \AA$ the C153 will fit within any local domains that may form within the 3-D solution structure. Therefore, we expect that these short-range interactions may cage C153 and thereby in part govern the observed dynamics and result in fast reorientation. Rotational time correlation functions (TCFs) were also reported for EAN cations and anions and fit to a two-time constant model that showed at $300 \mathrm{~K}$ anion organization persists at most on the order of a few hundred ps with a weighted average of 88 ps whereas cation persistence is much greater with a weighted average of 2500 ps. Considering that our results were measured at $295 \mathrm{~K}$ and these time constants were at $300 \mathrm{~K}$ there is reasonable agreement with a difference of $\sim 10 \%$. From ultrafast vibrational measurements using $\mathrm{SCN}^{-}$, dynamical heterogeneity was also confirmed with the observation of two populations that described the solute rotational dynamics [43]. However, the associated rotation times for the populations were reported to be the same within the experimental uncertainty at $\sim 2.5$ ps. Additional slower reorientations of $\sim 30$ ps were suggested that deplete any remaining anisotropy. The authors posited a set of domains, "charge-depleted" and "charge dense", to account for the two observed populations [43]. These ultrafast measurements agree with the general consensus from the literature regarding EAN spatial and dynamic heterogeneity, but the $\mathrm{SCN}^{-}$ultrafast dynamics are well beyond our time resolution.

In dilute EAN solution at $x_{I L}=0.1$ the bulk solution viscosity increases by $\sim 0.5 \mathrm{mPa}$ (about a 2-fold increase) but the even though absolute viscosity change is relatively small it is substantial enough that the viscous drag on $\mathrm{C} 153$ increases the rotational dynamics from $\sim 60 \%$ of the stick limit in $\mathrm{MeOH}$ to $\sim 90 \%$. Although we cannot assess the individual contributions from this data, the effect on the $\mathrm{C} 153$ rotational dynamics is evident. Further, for diluted EAN solutions the rotation times clearly demonstrate that with successively added EAN the solution is organizing with a predictable, smooth hydrodynamic-like variation. It is interesting to note that the rotation times steadily move away from the stick hydrodynamic prediction with increased EAN, although from our data the reason is not completely clear. Beyond $x_{I L}=0.6$ we noted that the rotational dynamics showed two time constants, with the faster time's relative weighting decreasing from $\sim 20 \%$ to $\sim 2 \%$ in neat EAN. Evidently, at $x_{I L}=0.5-0.6$ there is a 'balancing' point among all the competing 
effects of ion concentration and associated changes in ion mobility. Certainly, ion-ion interactions, hydrogen bond variations among the solution constituents, nanodomain formation all contribute to the solution heterogeneity that is sensed by C153. For our data, this is clearly manifested by the decreased value of the exponent $p(=0.82)$ from unity in the fitting of the average rotational time constants. Such a deviation has been shown in many ILs (including deep eutectic solvents, DESs) and explained as clear evidence of solution heterogeneity $[42,67,68]$. $C_{o b s}$ values clearly show the extent of deviation from ideal $\left(C_{o b s}=1\right)$ and we note that the solvent coupling is less than $50 \%$ of the stick limit in neat EAN. The most reasonable explanation would seem to be that C153 is in an environment where hydrogen bonding among ions is much stronger than hydrogen bond interactions with C153. Whether this is a simple caging effect or polar/apolar domain effect is not clear from our data and is most likely some combination of both. A report of rotational dynamics using rhodamine 6G (cationic dye) and fluorescein (anionic dye) showed that for charged dyes the rotational dynamics we not less than the stick limit and were super-stick at lower viscosity [47]. However, the authors did not present an analysis that determined the nonlinearity of the rotational data, e.g., a computed $p$-value, so we are unable to comment on this aspect in comparison to our C153 $p$-value. One final point to address is the reason why we only see two time constants for the EAN-rich solutions. We conjecture two possibilities here. First, it is reasonable to suggest that in the MeOH-rich solutions we simply do not have sufficient time resolution to resolve multiple time constants at these smaller mole fractions. Second, it is plausible that C153 is in a relatively rigid environment wherein the hydrogen bond interactions are such that the sum of all interactions between the ions, $\mathrm{MeOH}$ and $\mathrm{C} 153$ essentially lock C153 into a tight EAN/MeOH solvent shell. However, it is interesting to note that the magic-angle intensity decay is sensitive to solution composition near $x_{I L} \sim 0.3$, which underscores the importance of using various measurement strategies to study these complex systems. To resolve these questions further measurements are needed to examine more carefully the complexities of $\mathrm{EAN} / \mathrm{MeOH}$ solutions and we will be reporting on our findings for temperature dependent measurement in a subsequent report.

\section{Summary and Conclusions}

We have studied the EAN/MeOH binary solvent system over the entire range of IL mole fraction using the well-known, solvent sensitive, neutral fluorescent molecule C153. The interests here were to use SED hydrodynamics as a framework wherein we characterized the inherent heterogeneity of EAN and the EAN + methanol cosolvent system. C153 was chosen for this task, in part because as a neutral dye it reported on locales within the IL solution there were not associated with charged interactions, thereby avoiding the invocation of specific solvent-probe interactions that are not reasonably described by SED theory. As a diluent, $\mathrm{MeOH}$ solvates the EAN ions and viscosity measurements show that $\mathrm{MeOH}$ disrupts the EAN organization, as evidenced by an increased fluidity $\left(\eta^{-1}\right)$. Steady-state fluorescence results indicate that across the complete mole fraction range that the average energetics as measured by the emission maximum red shifted by $\sim 300 \mathrm{~cm}^{-1}$ and the emission width (FWHM) was invariant. The absorption peak maximum showed a $450 \mathrm{~cm}^{-1}$ red shift with a distinctive $170 \mathrm{~cm}^{-1}$ narrowing of the width at $x_{I L}=0.3$. Magic-angle intensity decays also indicated that the solution composition at $x_{I L}=0.3$ was significantly different but beyond $x_{I L}=0.5$ there was little change in time dependent emission. Fluorescence anisotropy decays yielded a single time constant for $x_{I L}<0.5$ and the rotation times were upwards of $90 \%$ stick hydrodynamics, which decreased to $\sim 80 \%$ stick at $x_{I L}=0.5$. For $x_{I L}>0.5$ the anisotropy decay was described by two time constants, and the faster time decreased from 500 to 240 ps with a concomitant change in fractional contribution from $20 \%$ down to $2 \%$. The slower time constant showed a steady increase from 1.0 to $2.2 \mathrm{~ns}$, but systematically deviated further away from the stick hydrodynamic limit as indicated by the continually decreased $C_{o b s}$ value that was $43 \%$ of the stick limit in neat EAN. The power law fit to the rotation times yielded a $p$ value of 0.82 , signifying the presence of dynamic heterogeneity in the $\mathrm{EAN} / \mathrm{MeOH}$ solution. Heterogeneity arises from 
the composite EAN ion-ion, ion-dipole (EAN-MeOH), ion solute (EAN-C153), and dipole solute $(\mathrm{MeOH}-\mathrm{EAN})$ interactions.

Supplementary Materials: The following are available online at https: / www.mdpi.com/article / 10.3390/suschem2040041/s1, Figure S1: Excess Viscosity Values for EAN/MeOH, Figure S2: Autocorrelation functions for Magic Angle Intensity Decays Fits, Figure S3: Polarized Emission Intensity Decays for $\mathrm{EAN} / \mathrm{MeOH}$.

Author Contributions: Conceptualization, M.P.H.; Methodology, M.P.H.; Validation, M.P.H.; Formal Analysis, M.P.H., S.M.R. and T.J.S.; Investigation, M.P.H., S.M.R. and T.J.S.; Resources, M.P.H.; Data Curation, S.M.R. and T.J.S.; Writing-Original Draft Preparation, M.P.H., S.M.R. and T.J.S.; Writing-Review and Editing, M.P.H.; Supervision, M.P.H.; Project Administration, M.P.H.; Funding Acquisition, M.P.H. All authors have read and agreed to the published version of the manuscript.

Funding: This research was funded by the Scholarly Incentive Grant Program and the Institute for Engaged Learning at SUNY Brockport.

Institutional Review Board Statement: Not applicable.

Informed Consent Statement: Not applicable.

Data Availability Statement: The data presented in this study are available on reasonable request from the corresponding author and are not publicly available.

Conflicts of Interest: The authors declare no conflict of interest. The funders had no role in the design of the study; in the collection, analyses, or interpretation of data; in the writing of the manuscript, or in the decision to publish the results.

\section{References}

1. Welton, T. Ionic liquids: A brief history. Biophys. Rev. 2018, 10, 691-706. [CrossRef]

2. Lei, Z.; Chen, B.; Koo, Y.-M.; MacFarlane, D.R. Introduction: Ionic Liquids. Chem. Rev. 2017, 117, 6633-6635. [CrossRef]

3. Greaves, T.L.; Drummond, C.J. Protic Ionic Liquids: Evolving Structure-Property Relationships and Expanding Applications. Chem. Rev. 2015, 115, 11379-11448. [CrossRef]

4. Castner, E.W.; Margulis, C.J.; Maroncelli, M.; Wishart, J.F. Ionic Liquids: Structure and Photochemical Reactions. Ann. Rev. Phys. Chem. 2011, 62, 85-105. [CrossRef] [PubMed]

5. Edward, W.; Castner, J.; Wishart, J.F. Spotlight on ionic liquids. J. Chem. Phys. 2010, 132, 120901. [CrossRef]

6. Greaves, T.L.; Drummond, C.J. Protic Ionic Liquids: Properties and Applications. Chem. Rev. 2008, 108, 206-237. [CrossRef] [PubMed]

7. Mariani, A.; Caminiti, R.; Ramondo, F.; Salvitti, G.; Mocci, F.; Gontrani, L. Inhomogeneity in Ethylammonium Nitrate-Acetonitrile Binary Mixtures: The Highest "Low q Excess" Reported to Date. J. Phys. Chem. Lett. 2017, 8, 3512-3522. [CrossRef] [PubMed]

8. Usula, M.; Matteoli, E.; Leonelli, F.; Mocci, F.; Marincola, F.C.; Gontrani, L.; Porcedda, S. Thermo-physical Properties of Ammonium-Based Ionic Liquid + N-methyl-2-pyrrolidone Mixtures at 298.15 K. Fluid Phase Equilib. 2014, 383, 49-54. [CrossRef]

9. Docampo-Álvarez, B.; Gómez-González, V.; Méndez-Morales, T.; Carrete, J.; Rodríguez, J.R.; Cabeza, Ó.; Gallego, L.J.; Varela, L.M. Mixtures of protic ionic liquids and molecular cosolvents: A molecular dynamics simulation. J. Chem. Phys. 2014, 140, 214502. [CrossRef] [PubMed]

10. Mariani, A.; Bonomo, M.; Wu, B.; Centrella, B.; Dini, D.; Castner, E.W.; Gontrani, L. Intriguing transport dynamics of ethylammonium nitrate-acetonitrile binary mixtures arising from nano-inhomogeneity. Phys. Chem. Chem. Phys. 2017, 19, 27212-27220. [CrossRef] [PubMed]

11. Zheng, Z.-P.; Fan, W.-H.; Roy, S.; Mazur, K.; Nazet, A.; Buchner, R.; Bonn, M.; Hunger, J. Ionic Liquids: Not only Structurally but also Dynamically Heterogeneous. Angew. Chem. Int. Ed. 2015, 54, 687-690. [CrossRef]

12. Zarrougui, R.; Dhahbi, M.; Lemordant, D. Transport and Thermodynamic Properties of Ethylammonium Nitrate-Water Binary Mixtures: Effect of Temperature and Composition. J. Solution Chem. 2015, 44, 686-702. [CrossRef]

13. Chagnes, A.; Tougui, A.; Carré, B.; Ranganathan, N.; Lemordant, D. Abnormal Temperature Dependence of the Viscosity of Ethylammonium Nitrate-Methanol Ionic Mixtures. J. Solution Chem. 2004, 33, 247-255. [CrossRef]

14. Russina, O.; Mariani, A.; Caminiti, R.; Triolo, A. Structure of a Binary Mixture of Ethylammonium Nitrate and Methanol. J. Solution Chem. 2015, 44, 669-685. [CrossRef]

15. Yalcin, D.; Christofferson, A.J.; Drummond, C.J.; Greaves, T.L. Solvation properties of protic ionic liquid-Molecular solvent mixtures. Phys. Chem. Chem. Phys. 2020, 22, 10995-11011. [CrossRef]

16. Rumble, C.A.; Uitvlugt, C.; Conway, B.; Maroncelli, M. Solute Rotation in Ionic Liquids: Size, Shape, and Electrostatic Effects. J. Phys. Chem. B 2017, 121, 5094-5109. [CrossRef] 
17. Araque, J.C.; Yadav, S.K.; Shadeck, M.; Maroncelli, M.; Margulis, C.J. How Is Diffusion of Neutral and Charged Tracers Related to the Structure and Dynamics of a Room-Temperature Ionic Liquid? Large Deviations from Stokes-Einstein Behavior Explained. J. Phys. Chem. B 2015, 119, 7015-7029. [CrossRef]

18. Usui, K.; Hunger, J.; Bonn, M.; Sulpizi, M. Dynamical heterogeneities of rotational motion in room temperature ionic liquids evidenced by molecular dynamics simulations. J. Chem. Phys. 2018, 148, 193811. [CrossRef] [PubMed]

19. Huang, Y.; Zhou, G.; Li, Y.; Yang, Z.; Shi, M.; Wang, X.; Chen, X.; Zhang, F.; Li, W. Molecular Dynamics Simulations of Temperature-Dependent Structures and Dynamics of Ethylammonium Nitrate Protic Ionic Liquid: The Role of Hydrogen Bond. Chem. Phys. 2016, 472, 105-111. [CrossRef]

20. Mariani, A.; Russina, O.; Caminiti, R.; Triolo, A. Structural Organization in a Methanol:Ethylammonium Nitrate (1:4) Mixture: A Joint X-ray/Neutron Diffraction and Computational Study. J. Mol. Liq. 2015, 212, 947-956. [CrossRef]

21. Barra, K.M.; Sabatini, R.P.; McAtee, Z.P.; Heitz, M.P. Solvation and Rotation Dynamics in the Trihexyl(tetradecyl)phosphonium Chloride Ionic Liquid/Methanol Cosolvent System. J. Phys. Chem. B 2014, 118, 12979-12992. [CrossRef]

22. Das, S.K.; Sarkar, M. Steady-state and time-resolved fluorescence behavior of coumarin-153 in a hydrophobic ionic liquid and ionic liquid-toluene mixture. J. Mol. Liq. 2012, 165, 38-43. [CrossRef]

23. Das, S.K.; Sarkar, M. Solvation and rotational relaxation of coumarin 153 and 4-aminophthalimide in a new hydrophobic ionic liquid: Role of N-H ... F interaction on solvation dynamics. Chem. Phys. Lett. 2011, 515, 23-28. [CrossRef]

24. Ito, N.; Arzhantsev, S.; Heitz, M.; Maroncelli, M. Solvation Dynamics and Rotation of Coumarin 153 in Alkylphosphonium Ionic Liquids. J. Phys. Chem. B 2004, 108, 5771-5777. [CrossRef]

25. Arzhantsev, S.; Ito, N.; Heitz, M.; Maroncelli, M. Solvation Dynamics of Coumarin 153 in Several Classes of Ionic Liquids: Cation Dependence of the Ultrafast Component. Chem. Phys. Lett. 2003, 381, 278-286. [CrossRef]

26. Kashyap, H.K.; Biswas, R. Solvation Dynamics of Dipolar Probes in Dipolar Room Temperature Ionic Liquids: Separation of Ion-Dipole and Dipole-Dipole Interaction Contributions. J. Phys. Chem. B 2010, 114, 254-268. [CrossRef]

27. Daschakraborty, S.; Ranjit, B. Stokes Shift Dynamics in (Ionic Liquid + Polar Solvent) Binary Mixtures: Composition Dependence. J. Phys. Chem. B 2011, 115, 4011-4024. [CrossRef] [PubMed]

28. Daschakraborty, S.; Biswas, R. Composition Dependent Stokes Shift Dynamics in Binary Mixtures of 1-Butyl-3-methylimidazolium Tetrafluoroborate with Water and Acetonitrile: Quantitative Comparison between Theory and Complete Measurements. J. Phys. Chem. B 2014, 118, 1327-1339. [CrossRef]

29. Pramanik, R.; Rao, V.G.; Sarkar, S.; Ghatak, C.; Setua, P.; Sarkar, N. To Probe the Interaction of Methanol and Acetonitrile with the Ionic Liquid N,N,N-Trimethyl-N-propyl Ammonium Bis(trifluoromethanesulfonyl) Imide at Different Temperatures by Solvation Dynamics Study. J. Phys. Chem. B 2009, 113, 8626-8634. [CrossRef]

30. Horng, M.L.; Gardecki, J.A.; Maroncelli, M. Rotational Dynamics of Coumarin 153: Time-Dependent Friction, Dielectric Friction, and Other Nonhydrodynamic Effects. J. Phys. Chem. A 1997, 101, 1030-1047. [CrossRef]

31. Hayes, R.; Imberti, S.; Warr, G.G.; Atkin, R. Amphiphilicity determines nanostructure in protic ionic liquids. Phys. Chem. Chem. Phys. 2011, 13, 3237-3247. [CrossRef]

32. Dasari, S.; Mallik, B.S. Nondiffusive Rotational Jump Dynamics in Ethyl Ammonium Nitrate. J. Phys. Chem. B 2018, 122, 9738-9746. [CrossRef] [PubMed]

33. Hunger, J.; Sonnleitner, T.; Liu, L.; Buchner, R.; Bonn, M.; Bakker, H.J. Hydrogen-Bond Dynamics in a Protic Ionic Liquid: Evidence of Large-Angle Jumps. J. Phys. Chem. Lett. 2012, 3, 3034-3038. [CrossRef] [PubMed]

34. Kobrak, M.N. Characterization of the Solvation Dynamics of an Ionic Liquid via Molecular Dynamics Simulation. J. Chem. Phys. 2006, 125, 064502. [CrossRef]

35. Samanta, A. Solvation Dynamics in Ionic Liquids: What We Have Learned from the Dynamic Fluorescence Stokes Shift Studies. J. Phys. Chem. Lett. 2010, 1, 1557-1562. [CrossRef]

36. Schroer, W.; Triolo, A.; Russina, O. Nature of Mesoscopic Organization in Protic Ionic Liquid-Alcohol Mixtures. J. Phys. Chem. B 2016, 120, 2638-2643. [CrossRef]

37. Kanzaki, R.; Mitsugi, T.; Fukuda, S.; Fujii, K.; Takeuchi, M.; Soejima, Y.; Takamuku, T.; Yamaguchi, T.; Umebayashi, Y.; Ishiguro, S.-I. Ion-ion interaction in room temperature ionic liquid 1-ethyl-3-methylimidazolium tetrafluoroborate studied by large angle X-ray scattering experiment and molecular dynamics simulations. J. Mol. Liq. 2009, 147, 77-82. [CrossRef]

38. Paul, A.; Samanta, A. Effect of Nonpolar Solvents on the Solute Rotation and Solvation Dynamics in an Imidazolium Ionic Liquid. J. Phys. Chem. B 2008, 112, 947-953. [CrossRef] [PubMed]

39. Chakrabarty, D.; Chakraborty, A.; Seth, D.; Sarkar, N. Effect of Water, Methanol, and Acetonitrile on Solvent Relaxation and Rotational Relaxation of Coumarin 153 in Neat 1-Hexyl-3-methylimidazolium Hexafluorophosphate. J. Phys. Chem. A 2005, 109, 1764-1769. [CrossRef]

40. Overbeck, V.; Schröder, H.; Bonsa, A.-M.; Neymeyr, K.; Ludwig, R. Insights into the translational and rotational dynamics of cations and anions in protic ionic liquids by means of NMR fast-field-cycling relaxometry. Phys. Chem. Chem. Phys. 2021, 23, 2663-2675. [CrossRef] [PubMed]

41. Overbeck, V.; Appelhagen, A.; Rößler, R.; Niemann, T.; Ludwig, R. Rotational correlation times, diffusion coefficients and quadrupolar peaks of the protic ionic liquid ethylammonium nitrate by means of $1 \mathrm{H}$ fast field cycling NMR relaxometry. J. Mol. Liq. 2021, 322, 114983. [CrossRef] 
42. LaRocca, M.M.; Baker, G.A.; Heitz, M.P. Assessing rotation and solvation dynamics in ethaline deep eutectic solvent and its solutions with methanol. J. Chem. Phys. 2021, 155, 034505. [CrossRef] [PubMed]

43. Johnson, C.A.; Parker, A.W.; Donaldson, P.M.; Garrett-Roe, S. An ultrafast vibrational study of dynamical heterogeneity in the protic ionic liquid ethyl-ammonium nitrate. I. Room temperature dynamics. J. Chem. Phys. 2021, 154, 134502. [CrossRef] [PubMed]

44. Conway, B.; Uitvlugt, C.; Maroncelli, M. Simulations of 1-Butyl-3-methylimidazolium Tetrafluoroborate + Acetonitrile Mixtures: Force-Field Validation and Frictional Characteristics. J. Phys. Chem. B 2018, 122, 7385-7393. [CrossRef] [PubMed]

45. Horng, M.L.; Gardecki, J.A.; Papazyan, A.; Maroncelli, M. Subpicosecond Measurements of Polar Solvation Dynamics: Coumarin 153 Revisited. J. Phys. Chem. 1995, 99, 17311-17337. [CrossRef]

46. Reynolds, L.; Gardecki, J.A.; Frankland, S.J.V.; Horng, M.L.; Maroncelli, M. Dipole Solvation in Nondipolar Solvents: Experimental Studies of Reorganization Energies and Solvation Dynamics. J. Phys. Chem. 1996, 100, 10337-10354. [CrossRef]

47. Kundu, N.; Roy, A.; Dutta, R.; Sarkar, N. Translational and Rotational Diffusion of Two Differently Charged Solutes in Ethylammonium Nitrate-Methanol Mixture: Does the Nanostructure of the Amphiphiles Influence the Motion of the Solute? J. Phys. Chem. B 2016, 120, 5481-5490. [CrossRef] [PubMed]

48. Russina, O.; Schroer, W.; Triolo, A. Mesoscopic Structural and Dynamic Organization in Ionic Liquids. J. Mol. Liq. 2015, 210, 161-163. [CrossRef]

49. Russina, O.; Sferrazza, A.; Caminiti, R.; Triolo, A. Amphiphile Meets Amphiphile: Beyond the Polar-Apolar Dualism in Ionic Liquid/Alcohol Mixtures. J. Phys. Chem. Lett. 2014, 5, 1738-1742. [CrossRef]

50. McAtee, Z.P.; Heitz, M.P. Density, Viscosity and Excess Properties in the Trihexyltetradecylphosphonium Chloride Ionic Liquid/Methanol Cosolvent System. J. Chem. Thermodyn. 2016, 93, 34-44. [CrossRef]

51. Jin, H.; Baker, G.A.; Arzhantsev, S.; Dong, J.; Maroncelli, M. Solvation and Rotational Dynamics of Coumarin 153 in Ionic Liquids: Comparisons to Conventional Solvents. J. Phys. Chem. B 2007, 111, 7291-7302. [CrossRef]

52. Chakraborty, A.; Seth, D.; Chakrabarty, D.; Setua, P.; Sarkar, N. Dynamics of Solvent and Rotational Relaxation of Coumarin 153 in Room-Temperature Ionic Liquid 1-Butyl-3-methylimidazolium Hexafluorophosphate Confined in Brij-35 Micelles: A Picosecond Time-Resolved Fluorescence Spectroscopic Study. J. Phys. Chem. A 2005, 109, 11110-11116. [CrossRef]

53. Ingram, J.A.; Moog, R.S.; Ito, N.; Biswas, R.; Maroncelli, M. Solute Rotation and Solvation Dynamics in a Room-Temperature Ionic Liquid. J. Phys. Chem. B 2003, 107, 5926-5932. [CrossRef]

54. Bose, S.; Adhikary, R.; Mukherjee, P.; Song, X.; Petrich, J.W. Considerations for the Construction of the Solvation Correlation Function and Implications for the Interpretation of Dielectric Relaxation in Proteins. J. Phys. Chem. B 2009, 113, 11061-11068. [CrossRef] [PubMed]

55. Funston, A.M.; Fadeeva, T.A.; Wishart, J.F.; Castner, E.W. Fluorescence Probing of Temperature-Dependent Dynamics and Friction in Ionic Liquid Local Environments. J. Phys. Chem. B 2007, 111, 4963-4977. [CrossRef]

56. Hu, C.M.; Zwanzig, R. Rotational friction coefficients for spheroids with the slipping boundary condition. J. Chem. Phys. 1974, 60, 4354-4357. [CrossRef]

57. Zwanzig, R.; Harrison, A.K. Modifications of the Stokes-Einstein formula. J. Chem. Phys. 1985, 83, 5861-5862. [CrossRef]

58. Jiang, Y.; Nadolny, H.; Kashammer, S.; Weibels, S.; Schroer, W.; Weingartner, H. The ion speciation of ionic liquids in molecular solvents of low and medium polarity. Faraday Discuss. 2012, 154, 391-407. [CrossRef]

59. Hu, X.; Lin, Q.; Gao, J.; Wu, Y.; Zhang, Z. Anion-cation and ion-solvent interaction of some typical ionic liquids in solvents with different dielectric constant. Chem. Phys. Lett. 2011, 516, 35-39. [CrossRef]

60. Annapureddy, H.V.; Dang, L.X. Pairing mechanism among ionic liquid ions in aqueous solutions: A molecular dynamics study. J. Phys. Chem. B 2013, 117, 8555-8560. [CrossRef] [PubMed]

61. Yee, P.; Shah, J.K.; Maginn, E.J. State of Hydrophobic and Hydrophilic Ionic Liquids in Aqueous Solutions: Are the Ions Fully Dissociated? J. Phys. Chem. B 2013, 117, 12556-12566. [CrossRef] [PubMed]

62. Hunger, J.; Stoppa, A.; Buchner, R.; Hefter, G. From Ionic Liquid to Electrolyte Solution: Dynamics of 1-N-Butyl-3-Nmethylimidazolium Tetrafluoroborate/Dichloromethane Mixtures. J. Phys. Chem. B 2008, 112, 12913-12919. [CrossRef]

63. Hemmateenejad, B.; Safavi, A.; Dorostkar, S. Aggregation of imidazolium based ionic liquids in binary methanol-water solvents: A linear solvation free energy relationship study. J. Mol. Liq. 2011, 160, 35-39. [CrossRef]

64. Mukherjee, P.; Crank, J.A.; Sharma, P.S.; Wijeratne, A.B.; Adhikary, R.; Bose, S.; Armstrong, D.W.; Petrich, J.W. Dynamic Solvation in Phosphonium Ionic Liquids: Comparison of Bulk and Micellar Systems and Considerations for the Construction of the Solvation Correlation Function, C(t). J. Phys. Chem. B 2008, 112, 3390-3396. [CrossRef] [PubMed]

65. Hayes, R.; Warr, G.G.; Atkin, R. Structure and Nanostructure in Ionic Liquids. Chem. Rev. 2015, 115, 6357-6426. [CrossRef]

66. Song, X.; Hamano, H.; Minofar, B.; Kanzaki, R.; Fujii, K.; Kameda, Y.; Kohara, S.; Watanabe, M.; Ishiguro, S.-I.; Umebayashi, Y. Structural Heterogeneity and Unique Distorted Hydrogen Bonding in Primary Ammonium Nitrate Ionic Liquids Studied by High-Energy X-ray Diffraction Experiments and MD Simulations. J. Phys. Chem. B 2012, 116, 2801-2813. [CrossRef]

67. Das, A.; Biswas, R. Dynamic Solvent Control of a Reaction in Ionic Deep Eutectic Solvents: Time-Resolved Fluorescence Measurements of Reactive and Nonreactive Dynamics in (Choline Chloride + Urea) Melts. J. Phys. Chem. B 2015, 119, 10102-10113. [CrossRef]

68. Hossain, S.S.; Paul, S.; Samanta, A. Liquid Structure and Dynamics of Tetraalkylammonium Bromide-Based Deep Eutectic Solvents: Effect of Cation Chain Length. J. Phys. Chem. B 2019, 123, 6842-6850. [CrossRef] 